Portland State University

PDXScholar

$1-24-2014$

\title{
Modeling Injury Outcomes of Crashes involving Heavy Vehicles on Texas Highways
}

Salvador Hernandez

Oregon State University

Follow this and additional works at: https://pdxscholar.library.pdx.edu/trec_seminar

Part of the Transportation Commons, and the Urban Studies and Planning Commons Let us know how access to this document benefits you.

\section{Recommended Citation}

Hernandez, Salvador, "Modeling Injury Outcomes of Crashes involving Heavy Vehicles on Texas Highways" (2014). TREC Friday Seminar Series. 63.

https://pdxscholar.library.pdx.edu/trec_seminar/63

This Book is brought to you for free and open access. It has been accepted for inclusion in TREC Friday Seminar Series by an authorized administrator of PDXScholar. Please contact us if we can make this document more accessible: pdxscholar@pdx.edu. 


\section{Background Intro}

- As the national economy continues to recover, the volume of large-truck (GVWR>10,000 lbs.) will also experience a similar recovery

- The increase in truck traffic poses an increased hazard to passenger vehicle traffic

- Large trucks were responsible for more fatalities than passenger vehicles in the U.S. (FHWA, 2010; NHTSA, 2009)

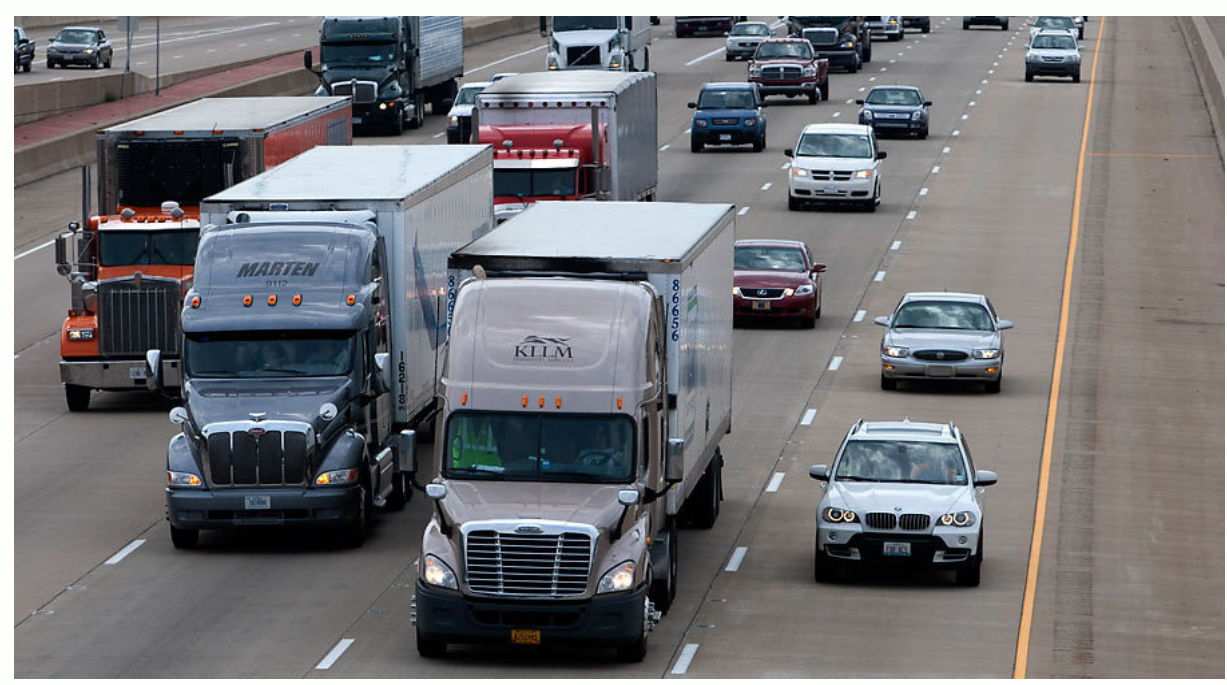




\section{Some Statistics}

- Large trucks accounted for roughly

- $4 \%$ of registered vehicles and

- $8 \%$ of VMT in 2008 ,

- $11 \%$ of motor vehicle involved crash deaths in 2008. (FHWA, 2010)

- Crash costs related to large truck collisions

\begin{tabular}{|l|r|}
\hline Injury Categories & Cost (2005 USD) \\
\hline Average cost per fatal crash & US\$3,604,518 \\
\hline Average cost per non-fatal crash & US\$195,258 \\
\hline Average cost per non-injury (PDO) & US\$15,114 \\
\hline
\end{tabular}

Source: Zaloshnja and Miller, 2006 


\section{Societal Impacts}

- Associated costs are remarkably high

- expenses related to loss of lives,

- medical attention, and insurance, and

- short term and long term physical and emotional effects

- Economic impacts

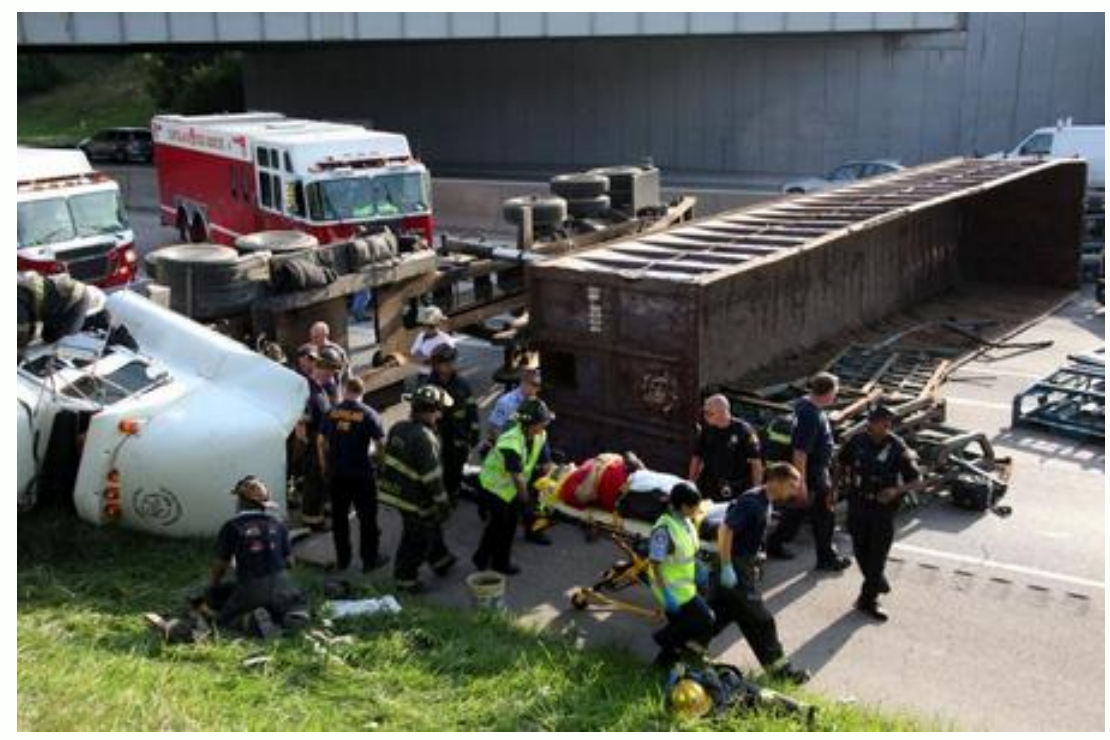




\section{Motivation}

- State of Texas faced the greatest economic losses of any state at $\$ 22.9$ billion dollars in 2008

- US from 2006 to $2010 \rightarrow \$ 107.4$ billion dollars

- Recent data indicated that in 2010 the State of Texas experienced:

- 3,023 deaths

- 59,660 serious injury crashes

- 82,685 people sustaining serious injuries

- Very few studies have investigated injury severities associated with large truck involved crashes, especially utilizing state specific crash databases 


\section{Research Objectives - Purely Exploratory}

- The primary objective of this study is:

- to analyze injury severity and understand and identify the factors of injury severity of large truck involved crashes

- A secondary objective is:

- to account for any "unobserved heterogeneity" (i.e., unobserved factors that may influence an injury outcome) related to human, vehicle, and road-environment

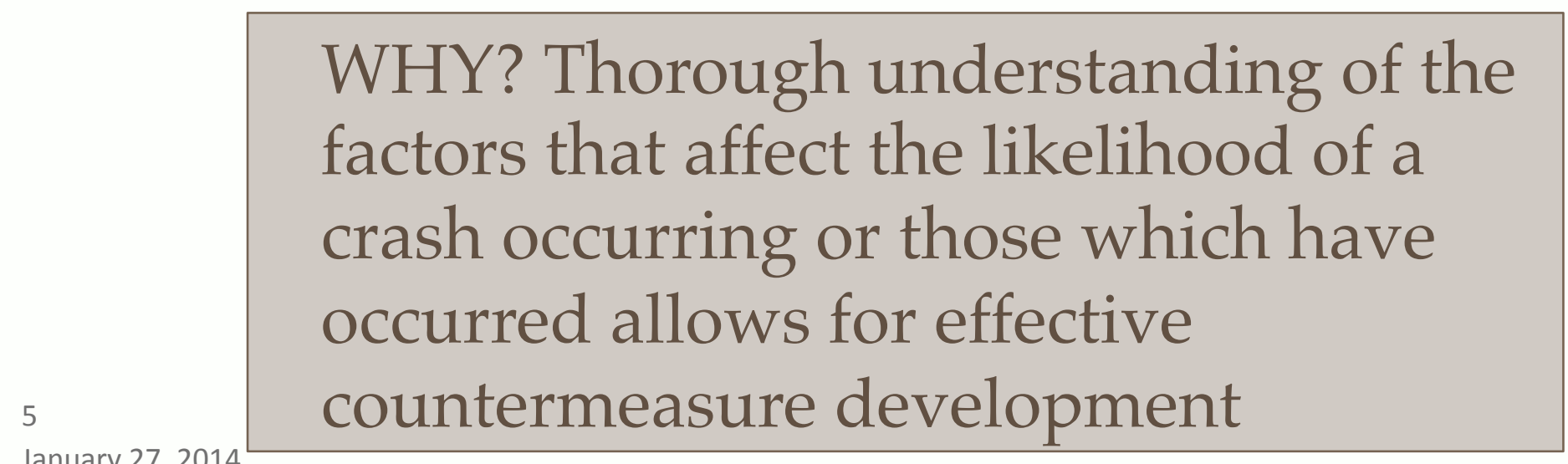




\section{Research Area}

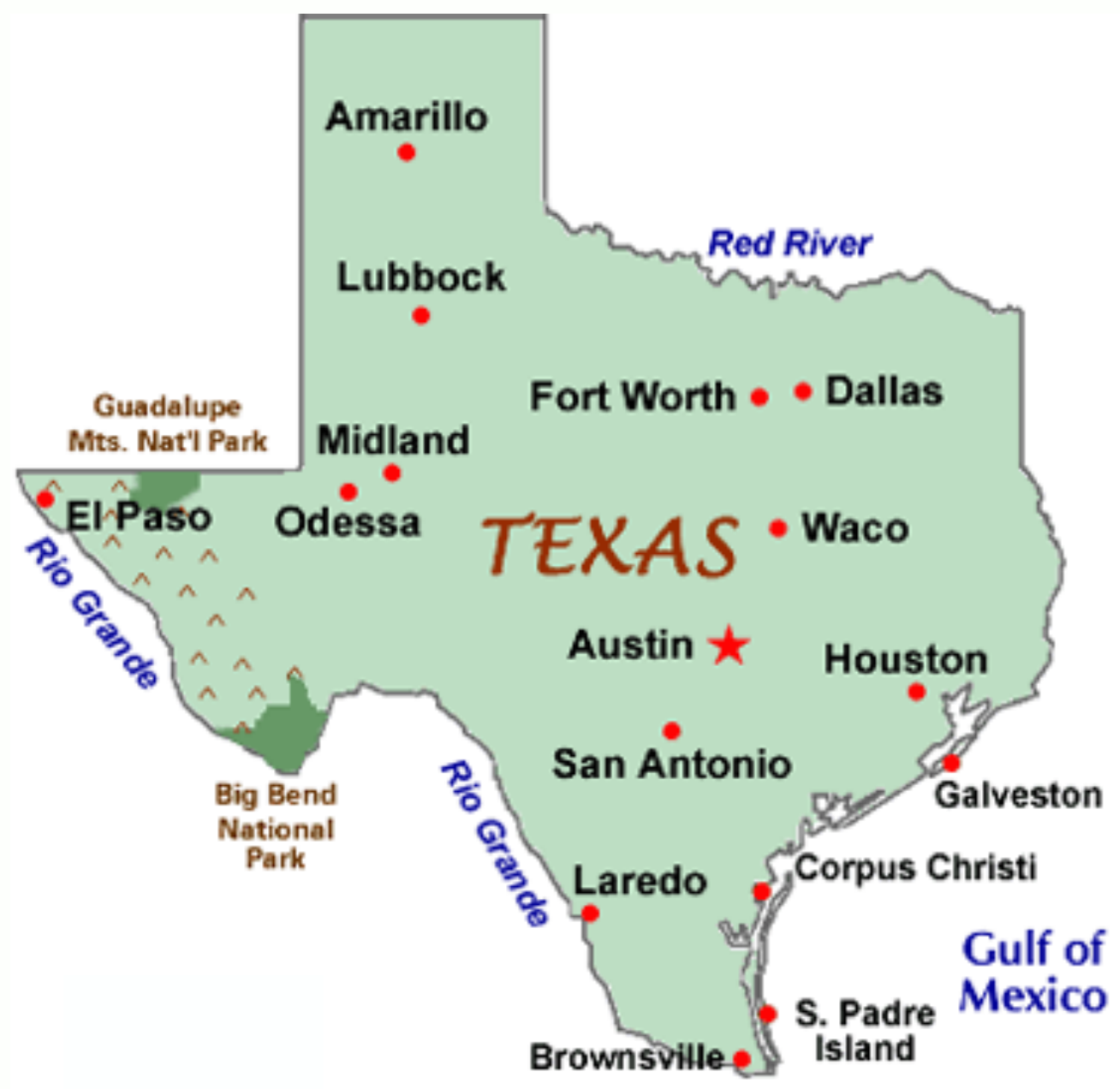




\section{Research Steps}

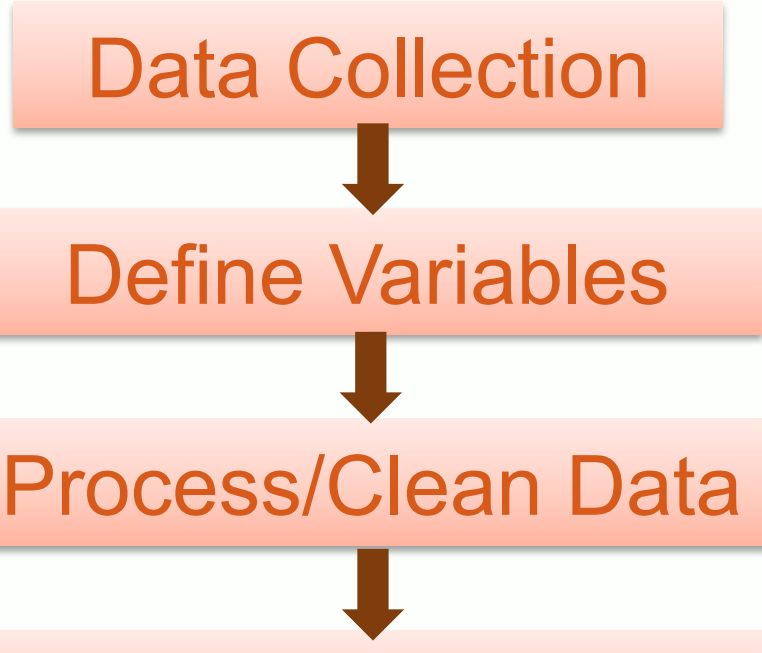

Injury Severity Modeling and Estimation

$\downarrow$

Variables and Scenario Explanation

Safety/ Policy Implications 


\section{Data - Texas Crash Data}

- The Crash Record Information System (CRIS) crash database of Texas was used to estimate injury severity models, where the KABCO severity scale was used to help define the injury outcomes as follows:

- fatal, incapacitating, non-incapacitating, possible, and no injury (Property- Damage-Only),

\begin{tabular}{|l|c|}
\hline Injury Levels & Police Reporting Scale \\
\hline Fatal & $\mathrm{K}$ \\
\hline Incapacitating & $\mathrm{A}$ \\
\hline Non-incapacitating & $\mathrm{B}$ \\
\hline Possible & $\mathrm{C}$ \\
\hline No injury (PDO) & $\mathrm{O}$ \\
\hline
\end{tabular}

Severity 


\section{Data Processing - Data Fusion}

2006 to 2010

- Interstate

Highways

- Large Trucks

- Vehicle and Person IDs

- Crash IDs

- Maximum Severity
SAS Data Processing/ Cleaning
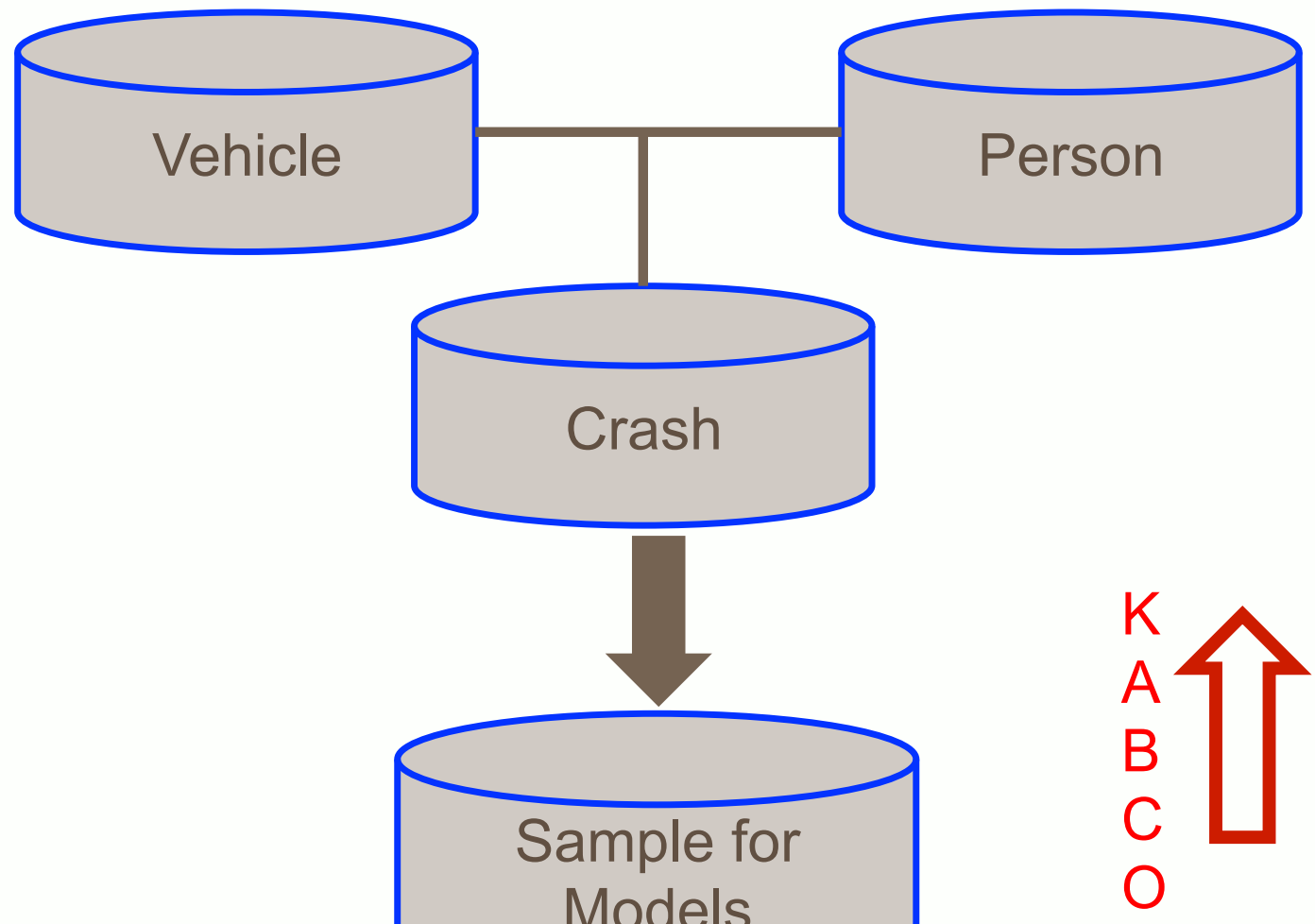

Figure: Data Processing Steps in SAS 


\section{Methodological Approach}

- Have detailed accident information, however the State of Texas is extremely large and diverse that:

- Unobserved heterogeneity is likely to exist among the population of large-truck crash-involved road users

- Due to differences in risk-taking behavior, physiological factors, driver training (especially for international drivers form neighboring Mexico), etc...

- Mixed logit (random parameters model) may be appropriate 


\section{Methodological Approach (Cont'd)}

- Standard Multinomial Logit (MNL) estimation assumes that the estimated parameters are the same (fixed) for all observations.

- Violations of this assumption can occur if there is some compelling reason (to believe) that parameters vary across observations in a way that cannot be accounted for in the model

- If not accounted for, may result in potential bias and erroneous statistical inferences 


\section{Methodological Approach (Cont'd)}

Define:

$$
S_{i n}=\boldsymbol{\beta}_{i} \boldsymbol{X}_{i n}+\varepsilon_{\text {in }}
$$

where

\begin{tabular}{|c|l|}
\hline Variable & Description \\
\hline $\boldsymbol{S}_{\text {in }}$ & $\begin{array}{l}\text { is a severity function determining the injury-severity } \\
\text { category } i \text { for large truck involved crashes } n ;\end{array}$ \\
\hline $\boldsymbol{X}_{\text {in }}$ & $\begin{array}{l}\text { is a vector of explanatory variables (e.g., driver, } \\
\text { vehicle, road, and environment variables); }\end{array}$ \\
\hline $\boldsymbol{\beta}_{i}$ & is a vector of estimable parameters; and \\
\hline $\boldsymbol{\varepsilon}_{i n}$ & is error term. \\
\hline
\end{tabular}




\section{Methodological Approach (Cont'd)}

If $\varepsilon_{\text {in }}$ 's are assumed to be generalized extreme value distributed,

where

$$
P_{n}(i)=\frac{E X P\left[\boldsymbol{\beta}_{i} \boldsymbol{X}_{i n}\right]}{\sum_{I} E X P\left[\boldsymbol{\beta}_{i} \boldsymbol{X}_{I n}\right]}
$$

\begin{tabular}{|c|l|}
\hline Variable & Description \\
\hline $\boldsymbol{P}_{n}(i)$ & $\begin{array}{l}\text { is probability of large truck involved } \\
\text { incident } n \text { having severity outcome with } I \\
\text { denoting all possible injury severity } \\
\text { outcomes as hereunto presented }\end{array}$ \\
\hline
\end{tabular}




\section{The Mixed Logit is:}

where

$$
P_{i n}=\int \frac{E X P\left[\boldsymbol{\beta}_{i} X_{i n}\right]}{\sum_{I} E X P\left[\boldsymbol{\beta}_{i} X_{I n}\right]} f(\boldsymbol{\beta} \mid \varphi) d \boldsymbol{\beta}
$$

$f(\boldsymbol{\beta} \mid \varphi)$ is the density function of $\beta$ with $\varphi$ referring to a vector of parameters of the density function (mean and variance).

- With this, $\boldsymbol{\beta}$ can now account for segment-specific variations of the effect of $\boldsymbol{X}$ on large truck involved crash probabilities, with the density function $f(\boldsymbol{\beta} \mid \boldsymbol{\varphi})$ used to determine $\boldsymbol{\beta}$. 


\section{Mixed Logit}

- Relaxes possible (independence of irrelevant alternatives) IIA problems with a more general errorterm structure.

- Can test a variety of distribution options for $\boldsymbol{\beta}$.

- Normal, log-normal, triangular, etc...

- Estimated with simulation based maximum likelihood.

- For more on the Mixed logit I refer you to:

Washington, S., M. Karlaftis, and F.L. Mannering. Statistical and econometric methods for transportation data analysis. Chapman and Hall/CRC, Boca Raton, FL, Second edition. 2011 


\section{Empirical Setting}

- Seek to model the maximum injury level sustained by the drivers involved in a crash

- Injury severities:

\begin{tabular}{|l|c|c|}
\hline Injury Severity & Observations & Percent \\
\hline Property damage only (PDO) & 18,223 & $88.96 \%$ \\
\hline Possible Injury (POSS) & 1,120 & $5.46 \%$ \\
\hline $\begin{array}{l}\text { Non-incapacitating injury (Non- } \\
\text { INCAP) }\end{array}$ & 601 & $2.93 \%$ \\
\hline Incapacitating injury (INCAP) & 463 & $2.26 \%$ \\
\hline Fatality (FATAL) & 78 & $0.38 \%$ \\
\hline
\end{tabular}

- Total observations $(\mathrm{N}=20,495)$ 
Time of day ( 1 if between $3 \mathrm{pm}$ to $7 \mathrm{pm}, 0$ otherwise)

Weather condition ( 1 if clear weather, 0 otherwise)

\section{Selected} Descriptive Statistics

Land-use pattern at crash location ( 1 if rural area, 0 otherwise)

Traffic flow at the time of crash (ADT per lane in each direction - veh/day/ln)

Month of the year (1 if summer (June to August), 0 otherwise)

Weather condition ( 1 if clear weather, 0 otherwise)

Shoulder width (right shoulder width (feet))

Time of the day ( 1 if between $3 \mathrm{pm}$ to $7 \mathrm{pm}, 0$ otherwise)

Land-use pattern at crash location ( 1 if urban area. 0 otherwise) Number of lanes on highways (1 if 4 lanes in one direction, otherwise)

Time of the day ( 1 if between 12 am to 6 am, 0 otherwise)

Months of year ( 1 if fall (September to December), 0 otherwise)

Land-use pattern at crash location ( 1 if rural area, 0 otherwise)

Genaer or the occupants (I if male, 0 otnerwise)

Time of the day ( 1 if between $3 \mathrm{pm}$ to $7 \mathrm{pm}, 0$ otherwise)

Traffic flow at the time of crash (ADT per lane in each direction

- veh/day/ln) (1 if veh/day/ln >2000, 0 otherwise)

Surface condition at the time of crash ( 1 if dry surface, 0 otherwise)

Age group ( 1 if age between 25 to 35, 0 otherwise)

Weather condition at the time of crash (1 if clear weather condition, 0 otherwise)

Light condition of street ( 1 if the surrounding area is dark but outside is lighted, 0 otherwise)

Land-use pattern at crash location ( 1 if urban area, 0 otherwise) Age group ( 1 if age between 45 to 55, 0 otherwise)

0.682

0.268

15397.3

0.257

0.682

19.727

0.203

0564

Surface condition at the time of crash (1 if dry surface, 0 otherwise)

0.428

0.159

0.318

0.268

0.944

0.203

0.985

Traffic flow at the time of crash (ADT per lane in each direction - veh/day/ln)

0.810

0.178

0.682

0.119

0.564

0.239

0.810
0.402

0.466

0.443

8845.23

0.437

0.466

3.555

0.402

0496

$0.495 \quad \begin{gathered}\text { Non- } \\ \text { Incapaci- }\end{gathered}$

tating

0.366

0.428

Injury

0.443

0.229

POSsIOIC

0.402

Injury

(0.4)

0.466

No-injury

0.324

0.496

0.427 


\section{Model Specification}

Five Utility functions used in the Mixed Logit Approach

$$
\begin{array}{ll}
S_{\text {FATAL }}=\sum \beta_{i} X_{i n}+\varepsilon_{i n} & \\
S_{I N C A P}=\sum \beta_{i} X_{i n}+\varepsilon_{i n} & \mathrm{~K} \\
S_{N O N-I N C A P}=\sum \beta_{i} X_{i n}+\varepsilon_{i n} & \mathrm{C} \\
S_{P O S S}=\sum \beta_{i} X_{i n}+\varepsilon_{i n} & \mathrm{O} \\
S_{P D O}=\sum \beta_{i} X_{i n}+\varepsilon_{i n} &
\end{array}
$$

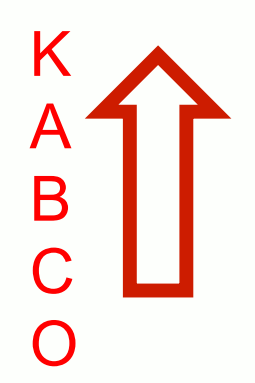




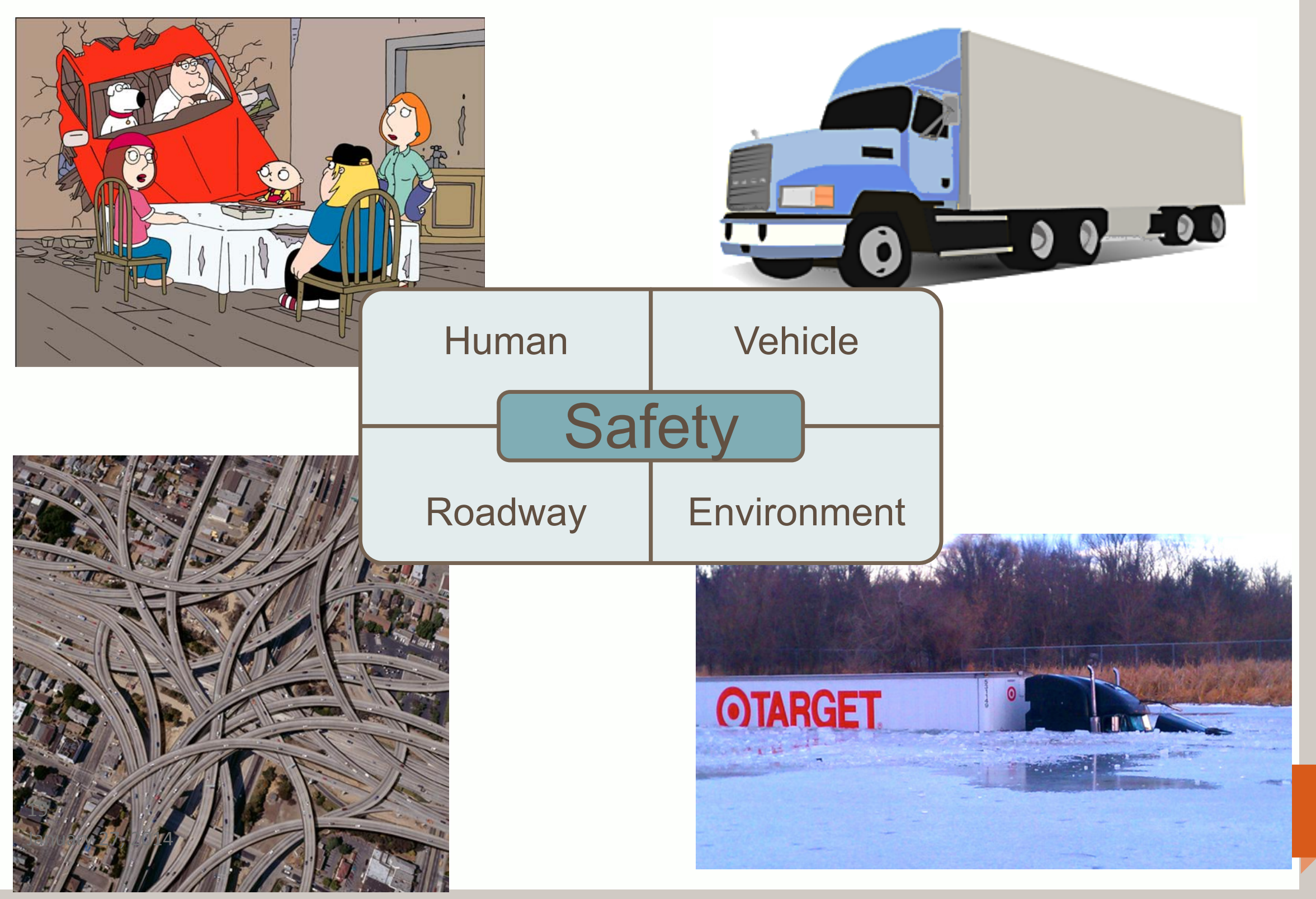




\section{Texas Case Study Findings}

\begin{tabular}{|l|}
\hline \multicolumn{2}{|c|}{ Drivers Characteristics } \\
\hline Male [POSS] \\
\hline 25-35 yrs [POSS] \\
\hline 45-55 yrs [PDO] \\
\hline
\end{tabular}

\begin{tabular}{|lr||}
\hline \multicolumn{2}{|c|}{ Temporal Characteristics } \\
\hline 3-7 PM [INCAP, POSS] \\
\hline 12-6 AM [NON-INCAP] \\
\hline Jun-Aug [INCAP] & $\mathbf{1}$ \\
\hline Sept-Dec [NON-INCAP] & $\checkmark$ \\
\hline
\end{tabular}

\section{Lighting Characteristics}

Dark but lighted [PDO] $\checkmark$

\begin{tabular}{|l|}
\hline \multicolumn{2}{|c|}{ Land use Characteristics } \\
\hline Rural [F, NON-INCAP] \\
\hline Urban [INCAP, PDO] \\
\hline
\end{tabular}

\begin{tabular}{|l|}
\hline \multicolumn{2}{|c|}{ Traffic Characteristics } \\
\hline ADT/LN/DAY $>2 \mathrm{~K}$ [POSS] \\
\hline ADT/LN/DAY [F] $\downarrow$ [PDO] \\
\hline
\end{tabular}

\begin{tabular}{|l|}
\hline Weather Characteristics \\
\hline Clear [F, PDO] 1 [INCAP] \\
\hline
\end{tabular}

Increase likelihood Decrease likelihood

\section{0}

January 27, 2014

\begin{tabular}{|l|}
\hline \multicolumn{2}{|c|}{ Road geometry Characteristics } \\
\hline 4-lane [NON-INCAP] \\
\hline Right shoulder width [INCAP] \\
\hline Level surface [F] \\
\hline Dry surface [POSS, PDO] \\
\hline
\end{tabular}
Oregon State 


\section{Random Parameter Findings}

- POSS: The male indicator

- Parameter normally distributed mean=-3.936 , S.D.=1.622

- This suggests that about $0.7 \%$ of large truck involved crashes involving male drivers on average were more likely to result in possible injuries

- PDO: Age group indicator between 45 to 55 years of age

- Parameter normally distributed mean=1.097, S.D.=1.866

- This implies that about $72.2 \%$ of large truck involved crashes with this age group (45 to 55 years' old drivers) on average were less likely to result in non-injury crashes 


\section{Research Hypothesis Testing}

Null hypothesis $-H_{0}$ : Statistically equivalent models FIX=RAN

Alternate hypothesis $-H_{A}$ : RAN is superior

$$
\chi^{2}=-2\left\lfloor L L_{F I X}\left(\beta^{F I X}\right)-L L_{R A N}\left(\beta^{R A N}\right)\right\rfloor
$$

The $\chi 2$ statistic for the likelihood ratio test with six degrees of freedom gave a value greater than the $99.99 \%(\chi 2=62.944)$ confidence interval, indicating that the mixed logit model (i.e., random parameter model) is statistically superior to the corresponding multinomial model (i.e., fixed parameter model). 


\section{Summary (Key Findings)}

- Higher traffic flow (i.e., vehicles per day per lane) reduces the likelihood of fatalities, but increases that of PDO crashes.

- Crashes occurring in rural settings result in a higher likelihood of fatalities and non-incapacitating injuries. In contrast, crashes occurring in urban settings result in a lower likelihood of incapacitating and PDO crashes. 


\section{Summary (Key Findings)}

- Time of day such as $3 \mathrm{pm}$ to $7 \mathrm{pm}$ results in lower likelihood of fatalities, incapacitating and possible injuries. Additionally, time of day such as 12 am to 6 am results in higher likelihood of non-incapacitating injuries.

- Summer is likely to increase likelihood of incapacitating injuries, whereas fall is likely to decrease likelihood of nonincapacitating injuries. 


\section{Future Work}

- Rural vs. Urban

- Time of Day

- Transferability of Models, e.g., Texas to Oregon etc... 


\section{Thank You!}

\section{Sources:}

Islam, M.B., Hernandez, S., 2013. Modeling Injury Outcomes of Crashes involving Heavy Vehicles on Texas Highways. Transportation Research Record: Journal of the Transportation Research Board, (In Print).

Family Guy Image: http: / / www.entertainmentearth.com/prodinfo.asp? number=AMFGG07\#.UuIEomTTkTI

Target Semi Truck Image: http: / / www.dailymail.co.uk/ news/ article-2083323/Target-truckdriver-skids-icy-pond-8-feet-deep-water-Minnesota.html

Spaghetti Bowl Interchange: http: / / pastmycurfew.com/ my-top-10-1-favorite-man-madewonders / 